\title{
Revision total hip arthroplasty with cemented femoral component
}

\author{
Habib Nouri • Sofiene Kallel • Mohamed Hadj Slimane • \\ Mohamed Hédi Meherzi • Moez Ouertatani • \\ Salahedine Karray
}

Received: 17 October 2007 / Accepted: 21 March 2008 / Published online: 26 April 2008

(C) The Author(s) 2008

\begin{abstract}
We reviewed retrospectively the results of 28 hips (25 patients) after revision of the femoral component with use of a cemented stem, because of aseptic loosening. The mean duration of follow-up was 4.43 years (range 2-12 years). Over the course of the study period, repeat revision was done in 4 hips after an average of 4.45 years. Three hips had a repeat revision of the femoral component because of aseptic loosening and one for a deep infection. The rate of loosening of the femoral component was $32.4 \%$ (9 hips) at an average of 5.22 years. The 5-year survival rate was $76.9 \%$ with mechanical failure as end point; and $90 \%$ with rerevision of femoral component because of aseptic loosening as end point. The cement mantle was the principal factor, which was significantly associated with a better survival rate of femur fixation $(P<0.05)$. No correlation was noted between quality of bone loss at the time of revision, bone graft or the use of long stems, and the survival rate of femoral component. By improving the cementing technique and in selected patients, the use of cemented femoral stem could be a good alternative for aseptic loosening THA.
\end{abstract}

Keywords Aseptic loosening - Total hip arthroplasty . Revision $\cdot$ Cement $\cdot$ Femoral component

\section{Introduction}

Reports from the 1980s showed discouraging long-term survival following revision total hip arthroplasty with

H. Nouri $(\bowtie) \cdot$ S. Kallel · M. Hadj Slimane $\cdot$ M. H. Meherzi ·

M. Ouertatani $\cdot$ S. Karray

Department of "Adult" Surgery,

Institute KASSAB of Orthopaedic Surgery,

2010 Mannouba, Tunisia

e-mail: nourihabib@yahoo.fr cement $[1,14]$. Recently, many authors have reported the results of revision total hip arthroplasty performed with use of modern cementing techniques [16, 20]. The rates of femoral loosening in those series ranged from 6 to $36 \%$ at about 10 years, with most of the rates ranging from 10 to $15 \%$. Several studies have identified factors that are predictive of failure, including bone quality [11, 22], patient age $[10,22]$, and cement mantle quality $[6,18]$. The purpose of the present study was to examine the results for cemented revision femoral components and to determine which clinical and surgical factors are predictive of failure.

\section{Materials and methods}

Between 1989 and 2005, 34 total hip arthroplasties (THA) were revised for mechanical loosening, with use of a cemented femoral component. Six hips were excluded in patients who had a follow up less than 2 years. Twentyeight hips in 25 patients were reviewed retrospectively with a mean follow up of $4.43 \pm 3.07$ years (range 2-12 years). There were 14 males and 11 females with a mean age of $58.93 \pm 15.67$ years (range 31-84 years) at the moment of revision. The procedure was done in the right hip in 12 cases $(42.9 \%)$ and in the left hip in 16 cases $(57.1 \%)$. Three patients had bilateral revision.

The diagnosis that led to the primary THA included osteoarthritis in 10 cases (35.7\%), rheumatoid arthritis in 8 cases $(28.6 \%)$, fracture in 6 cases $(21.4 \%)$, osteonecrosis in 3 cases $(10.7 \%)$ and osteomyelitis in 1 case $(3.6 \%)$. All these prostheses were cemented. The mean interval since the first operation was $11.07 \pm 6.68$ years (range 2-28 years).

The diagnosis that led to the revision procedure was aseptic loosening which was associated to a periprosthetic fracture in two cases. Twenty-three hips $(82.1 \%)$ had 
revision of both femoral and acetabular components and five hips (17.9\%) had revision of the femoral stem only.

Biologic analyses were normal, and intraoperative cultures were negative in all patients.

\section{Surgical procedure}

A lateral approach was used in 15 cases, a trochanterotomy was used in 11 cases and a transfemoral approach in 2 cases. Cancellous allograft bone was used in 11 hips. Milled femoral head allografts were impacted proximally around the femoral rasp in order to reconstruct the calcar region just before cementing definitive implant. The new femoral stems included a classic stem $(<210 \mathrm{~mm})$ in 23 cases, and a long stem $(>210 \mathrm{~mm})$ in 5 cases. The two periprosthetic fractures were treated by plate after cementing a short femoral stem. The generation of the cementing technique that was based on Harris's criteria as described by Wixson and Lautenschlager [24] (Table 1). In our study, we used first generation cementing technique for all patients.

\section{Clinical evaluation}

Clinical data were collected retrospectively from the medical register. The functional status of each hip was assessed with Postel Merle d'Aubigné score preoperatively and at the last follow up.

\section{Radiographic evaluation}

A set of radiographs was available for all patients. It included preoperative anteroposterior and lateral views, immediately postoperatively anteroposterior view, and at the last follow up anteroposterior and lateral views. Preoperative radiographs were used to evaluate bone quality. Bone loss was classified according to the system described by Mallory [15] (Table 2). The quality of the cement mantle on immediately postoperative radiographs was evaluated with use of the criteria described by Barrak [2] (Table 3). The most recent radiographs were compared with the latest ones to evaluate radiographic loosening according to the criteria described by Harris et al. [8] (Table 4).

Data analysis

Kaplan-Meier survival curves with end points defined as rerevision for aseptic loosening of the femoral components, and mechanical failure of the femoral components (definite or probable radiographic loosening) were calculated for all patients: patients younger than 55 years of age and older, patients with a cement mantle postoperatively A or B and C or D and patients with bone loss type I or II and patients with loss of bone type III. Breslow test was performed on

Table 2 Classification of femoral bone loss according to system of Mallory [15]

\begin{tabular}{ll}
\hline Type I & $\begin{array}{l}\text { Medullary contents intact, cortical bone intact } \\
\text { Type II }\end{array}$ \\
Type IIIA & $\begin{array}{c}\text { Medullary contents deficient, cortical bone intact } \\
\text { deficient to lesser trochanter }\end{array}$ \\
Type IIIB & $\begin{array}{l}\text { Medullary contents deficient, cortical bone } \\
\text { deficient to level between lesser trochanter } \\
\text { and isthmus }\end{array}$ \\
Type IIIC & $\begin{array}{c}\text { Medullary contents deficient, most of proximal } \\
\text { part of femur deficient }\end{array}$ \\
&
\end{tabular}

Table 3 Classification of immediate postoperative femoral cement mantle according to criteria of Barrack et al. [2]

\begin{tabular}{ll}
\hline Category A & $\begin{array}{c}\text { Complete filling of medullary cavity } \\
\text { by cement; whiteout at cement-bone interface }\end{array}$ \\
Category B & $\begin{array}{l}\text { Slight radiolucency at cement-bone interface } \\
\text { Radiolucency involving } 50-99 \% \text { of cement-bone } \\
\text { Category C }\end{array}$ \\
Category D & $\begin{array}{c}\text { Radiolucency involving } 100 \% \text { in any projection, } \\
\text { or tip of stem uncovered }\end{array}$ \\
\hline
\end{tabular}

Table 1 Harris's definitions of first, second, and third generation cementing techniques according to Wixson and Lautenschlager [24]

\begin{tabular}{|c|c|c|}
\hline First generation & Second generation & Third generation \\
\hline Hand-mix cement & Hand-mix cement & Vacuum-centrifugation of cement \\
\hline Leave cancellous bone & $\begin{array}{l}\text { Remove cancellous bone to } \\
\text { near-endosteal surface }\end{array}$ & Remove cancellous bone to near endosteal surface \\
\hline Venting of femoral canal & Distal cement restrictor & Distal cement restrictor \\
\hline Minimal canal preparation & Brushing and pulsatile irrigation of canal & Brushing and pulsatile irrigation of canal \\
\hline Irrigate and suction canal & Irrigate and suction canal & $\begin{array}{l}\text { Irrigate, pack, and dry canal, Irrigate with pulsatile lavage, } \\
\text { pack with adrenaline-soaked sponges, and dry canal }\end{array}$ \\
\hline $\begin{array}{l}\text { Manual cement insertion } \\
\text { with fingers }\end{array}$ & Retrograde injection with cement gun & Retrograde injection with cement gun and pressurization \\
\hline $\begin{array}{c}\text { Manual positioning into } \\
\text { neutral stem position }\end{array}$ & $\begin{array}{l}\text { Manual positioning or early distal } \\
\text { centralization methods }\end{array}$ & $\begin{array}{l}\text { Distal and proximal centralizers for an even cement } \\
\text { mantle and neutral position }\end{array}$ \\
\hline
\end{tabular}


Table 4 Classification of radiographic loosening according to criteria of Harris et al. [8]

\begin{tabular}{ll}
\hline Definite loosening & $\begin{array}{c}\text { Stem migration (medial collar to calcar; } \\
\text { if no collar, then tip of prosthesis } \\
\text { to calcar); stem/cement mantle fracture } \\
\text { Continuous radiolucent line surrounding } \\
\text { entire cement mantle on any view } \\
\text { Padiolucent zone involving 50-99\% } \\
\text { of cement-bone interface on any } \\
\text { view and radiolucency not present } \\
\text { immediately postoperatively } \\
\text { Possible loosening }\end{array}$ \\
Stable & None of above criteria met \\
\hline
\end{tabular}

the results of the Kaplan-Meier survival analysis to determine significant differences between groups.

Clinical, radiographic, and surgical factors that had a significant association with failure were identified with use of Chi-square tests. The level of significance was set at $P<0.05$.

\section{Results}

At the time of the study, 24 hips remained in situ. Three femoral components had been revised because of aseptic loosening and one because of deep infection. The mean time to rerevision was $4.5 \pm 3.11$ years. Three rerevisions occurred in males and one in a woman but this was not significant $(P=0.353)$.

\section{Clinical evaluation}

The PMA score improved from an overall mean of 10.56/ 18 points preoperatively to $16.13 / 18$ at the latest follow up (range 9-18). Fifteen hips (53\%) were rated as excellent (PMA $=17-18$ points), 7 hips $(25 \%)$ were rated as good $(15-16$ points), 1 hip as fare (13 points) and 3 as poor $(<12$ points).

The mean pain score was 2.73 preoperatively compared with 5.2/6 at the latest follow up. Fifteen hips had no or slight pain.

\section{Radiographic analysis}

Classification of femoral bone loss according to system of Mallory [15] is presented in Fig. 1. No difference was noted between the preoperative bone quality and the radiographic failure after revision.

The postoperative mantle of cement was graded as category A for 12 hips (42.9\%), category B for 7 hips (25\%), category $\mathrm{C}$ for 5 hips $(17.9 \%)$ and category D for 4 hips $(14.3 \%)$. There was no correlation between the quality of bone and the quality of the cement mantle. Analysis of

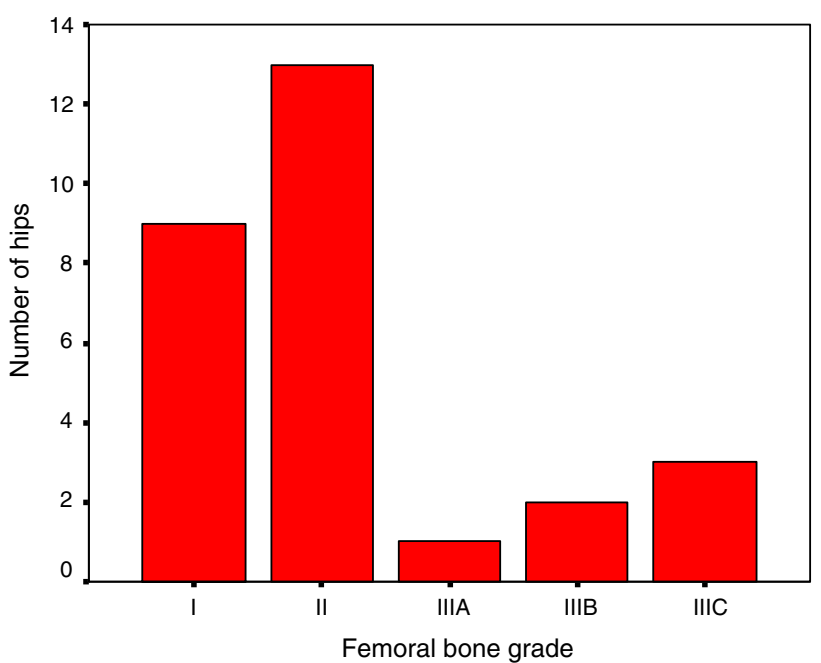

Fig. 1 Illustration showing the Mallory [15] classification of femoral bone quality

femoral component fixation according to Harris et al. [8] $3^{21}$ demonstrated that 12 hips $(42.9 \%)$ were stable, 7 hips (25\%) were possibly loose, 3 hips $(10.7 \%)$ were probably loose, and 6 hips $(21.4 \%)$ were definitely loose. Only three hips with definitely loose were rerevised. The other patients refused reoperation.

Hips in which the cement mantle was classified as category $\mathrm{C}$ or $\mathrm{D}$ (9 cases) were more likely to have probably or definitely loosening $(P<0.001)$ and were more likely to experience mechanical failure than hips in which category of cement mantle was A or B. Hips in which the cement mantle was classified as category A have significantly better long term fixation than hips in all other categories $(P<0.001)$.

\section{Complications}

Dislocation occurred in one hip (3.6\%). There were no recurrence and no reoperation was necessary. Non-union of the trochanter occurred in 1 of the 11 hips treated with trochanterotomy (9\%). There was a deep infection in one hip (3.6\%) that occurred 1 year after revision. A two-stage revision was done with good evolution at 3 years of follow up. None of the patients had clinically evident deep venous thrombosis or pulmonary emboli.

\section{Component survival}

Kaplan-Meier analysis revealed that the 5-year survival rate was $76.9 \%$ with mechanical failure (hips probably or definitely loose) as end point; and $90 \%$ with rerevision of femoral component because of aseptic loosening. The 5-year survival rate with mechanical failure as end point was significantly higher in hips in which the cement mantle was 
classified as category A or B $(88.8 \%)$ than in hips in which cement mantle was classified as category C or D $(53.3 \%)$ $(P=0.0027)$. No difference in survival rate had been noted according to gender, age, quality of femoral bone, and the length of the femoral stem.

\section{Discussion}

The complexity of femoral revision arthroplasty is clearly evident when the vast array of techniques used for similar types of bone loss is considered. Revision with cement may be attractive to the surgeon and patient. It provides immediate femoral fixation and presumably a high likelihood of pain relief [4]. Although, many authors reported the difference in longevity of femoral fixation between primary and revision THA [16].

The less satisfactory results after revision of femoral components with cement are predictable, given the compromised femoral bone stock in many patients [3]. Hunter et al. [12] reported a $22 \%$ rate of excision arthroplasty after 140 femoral revision arthroplasties that had been performed with cement. Engelbrecht et al. [7] later reported that $31 \%$ of 138 cemented revision femoral components had radiographic evidence of loosening at an average of 7.4 years. A likely explanation for the substantial rate of loosening that was observed in the present study $(32.1 \%)$ is that it is difficult to obtain good cement interdigitation with the cancellous microstructure of bone. Bone removal at the time of the initial implantation of the femoral stem, subsequent bone loss caused by mechanical failure of the THA, and during canal preparation for revision often left little cancellous bone at the time of the revision with cement. The failure to obtain good cement-bone interface in many patients is reflected by the high percentage of grade $\mathrm{C}$ and $\mathrm{D}$ cement mantle (32.1\%). Notably, this subgroup was associated with the highest rate of failure $(P<0.05)$. Dohmae et al. [5] demonstrated the importance of interdigitation of the cement with cancellous bone in an in vitro model in which a first revision model was compared with a primary arthroplasty model. They showed that the shear strength at the cement-bone interface was reduced by $80 \%$ in the revision model. The shear strength was reduced by $93 \%$ in a second revision model. These results are consistent with those reported by Retpen et al. [19] and Kavanagh et al. [13], who demonstrated that the rates of clinical and radiographic failures that were observed in association with second and third revision hip arthroplasties performed with use of cement were increased when compared with the rates that were observed in association with primary THA and first revision.

Despite, the results that discouraged the use of cemented femoral stems during THA revision, recent evidence [11, 17] has supported this technique as an acceptable mode of reconstruction in selected patients by improving the cementing technique. Studies investigating the use of modern cementation techniques in groups ranging in size from 43 to 399 hips have shown encouraging intermediate and long-term results $[17,20]$, renewing interest in this technique of femoral revision.

Our study highlights the importance of a good technique of cementing in the longevity of femoral fixation. This includes a good debridment of soft tissue membrane and neocortex in the medullary canal, which led the cement to interdigitate into bone more effectively, and the use of cement gun delivery system that plugged the distal part of the canal [23]. Mallory [15] added support to the argument for the use of second generation cementing technique for fixation in revision of femoral component that has become aseptically loose. They report a rate of repeat revision for aseptic loosening of the femoral component of $16 \%$ after an average follow up of 15.1 years. Haydon et al. [9] found that the 10-year survival rate associated with third generation cementing techniques was significantly better than that associated with second generation techniques when rerevision because of aseptic loosening was used as the end point (94\% compared with $85 \% ; P<0.05$ ). In our study, we used first generation cementing technique for all patients: finger packing of the cement without use of the medullary plug or cement gun, no centrifugation, no pressurization, or reduction of porosity.

In the current series, revision was done in 13 hips with quality of bone stock grade I, 9 hips grade II and in 6 hips grade IIIA, B or C. When the population was segregated into subsets according to both the grading of the mantle of cement and the classification of bone stock, the small sample size of each subset precluded statistical conclusions regarding improved durability of the femoral component in hips that had better quality of bone stock or grades for cementing.

To gain additional fixation, some authors suggested the use of long-stem femoral component extending distal to the isthmus of the femur [4]. Hultmark et al. [11] demonstrated that the 10-year rate of survival free of mechanical failure was $93 \%$ for long-stem implants but only $79 \%$ for standard length stems. With the number of patients with long stem in our series, we could not find a difference in longevity of femoral fixation according to femoral component length.

The best results of femoral revision with cemented stems were reported by Schreurs et al. [21]. They obtained a survival rate of $100 \%$ at a mean of 10.4 years with repeat revision of the femoral component for any reason as the end point in 25 patients treated with use of impaction bone grafting and a cemented polished femoral stem according to a specific technique. Although, 22 of the 33 femoral stems used $(66.6 \%)$ had migrated. In seven cases, the migration 
was more than $5 \mathrm{~mm}$. The authors underlined the necessity to restore femoral bone stock for long-term longevity of the reconstruction. Nevertheless, it is a demanding technique that needs special devices and strict adherence to proper technique. In our study, we did not see any difference in the 5 -year survival rate with use of impacted cancellous bone allograft.

Other factors had been associated with good results especially in males and elderly patients ( $>60$ years) [16]. In several series, the age of the patient has been a determining factor in the durability of the femoral fixation after revision. Stromberg et al. [22] reported a rate of repeat revision of the femoral component of $19 \%$ (13 of 67 hips) at 2.9 years in patients who were 55 years old or less and in whom first generation cementing techniques had been used. Herberts et al. [10] reported on a Swedish population of patients who were 55 years old or less at the time of revision with use of second generation cementing techniques; after 4 years, 14 (21\%) of 66 hips had repeat revision because of aseptic loosening of the femoral component.

In the current study, the average of follow up is insufficient to detect effects of such factors on survival rate. It seems that at a short-term follow up, quality of the cement mantle is the most important factor on which depends the quality of fixation of the femoral stem. The other factors, such as age, sex, and the design of the femoral stem could intervene to determine long-term survival rate of hip reconstruction.

Unfortunately, the numbers of patients evaluated in the current study did not allow statistical analysis of the various subgroups proposed by the staging system and it would seem that the number of patients required for this type of analysis will require a collaborative multicenter study.

\section{Conclusion}

In view of the results of the present study and what is known about factors contributing to the success of femoral revision with use of cement, we now assess the quality of the remaining cancellous bone at the time of revision and individualize the type of femoral fixation on the basis of the likelihood of obtaining good cement-bone interface as well as other patients-related factors such as age, activity level, medical status and pattern of femoral bone loss.

Conflict of interest statement No funds were received in support of this study.

Open Access This article is distributed under the terms of the Creative Commons Attribution Noncommercial License which permits any noncommercial use, distribution, and reproduction in any medium, provided the original author(s) and source are credited.

\section{References}

1. Amstutz HC, Ma SM, Jinnah RH, Mai L (1982) Revision of aseptic loose total hip arthroplasties. Clin Orthop 170:21-33

2. Barrack RL, Mulroy RD Jr, Harris WH (1992) Improved cementing techniques and femoral component loosening in young patients with hip arthroplasty. A 12-year radiographic review. J Bone Joint Surg Br 74:385-9

3. Callaghan JJ, Salvati EA, Pellicci PM, Wilson PD, Ranawat CS (1985) Results of revision for mechanical failure after cemented total hip replacement, 1979 to 1982 . A two to five-year follow-up. J Bone Joint Surg 67-A:1074-1085

4. Davis CM, Berry DJ, Harmsen WS (2003) Cemented revision of failed uncemented femoral components of total hip arthroplasty. J Bone Joint Surg Am 85:1264-1269

5. Dohmae Y, Bechtold JE, Sherman RE, Puno RM, Gustilo RB (1988) Reduction in cement-bone interface shear strength between primary and revision arthroplasty. Clin Orthop 236:214-20

6. Eisler T, Svensson O, Iyer V, Wejkner B, Schmalholz A, Larsson H, Elmstedt E (2000) Revision total hip arthroplasty using thirdgeneration cementing technique. J Arthroplasty 15:974-81

7. Engelbrecht DJ, Weber FA, Sweet MB, Jakim I (1990) Long-term results of revision total hip arthroplasty. J Bone Joint Surg Br 72:41-5

8. Harris WH, McCarthy JC Jr, O’Neill DA (1982) Femoral component loosening using contemporary techniques of femoral cement fixation. J Bone Joint Surg Am 64:1063-7

9. Haydon CM, Mehin R, Burnett S, Rorabeck CH, Bourne RB, McCalden RW, MacDonald SJ (2004) Revision total hip arthroplasty with use of a cemented femoral component. Results at a mean of ten years. J Bone Joint Surg Am 86:1179-1185

10. Herberts P, Ahnfelt L, Malchau H, Stromberg C, Andersson GB (1989) Multicenter clinical trials and their value in assessing total joint arthroplasty. Clin Orthop 249:48-55

11. Hultmark P, Karrholm J, Stromberg C, Herberts P, Mose CH, Malchau H (2000) Cemented first-time revisions of the femoral component: prospective 7 to 13 years' follow-up using secondgeneration and third-generation technique. J Arthroplasty 15:551-61

12. Hunter GA, Welsh RP, Cameron HU, Bailey WH (1979) The results of revision of total hip arthroplasty. J Bone Joint Surg Br 61:419-21

13. Kavanagh BF, Fitzgerald RH Jr (1987) Multiple revisions for failed total hip arthroplasty not associated with infection. J Bone Joint Surg Am 69:1144-9

14. Kavanagh BF, Ilstrup DM, Fitzgerald RH Jr (1985) Revision total hip arthroplasty. J Bone Joint Surg Am 67:517-26

15. Mallory TH (1988) Preparation of the proximal femur in cementless total hip revision. Clin Orthop 235:47-60

16. Mulroy WF, Harris WH (1996) Femoral component. a fifteenyear-average follow-up study for aseptic loosening of the revision total hip arthroplasty with use of so-called second-generation cementing techniques. J Bone Joint Surg Am 78:325-30

17. Raut VV, Siney PD, Wroblewski BM (1996) Outcome of revision for mechanical stem failure using the cemented Charnley's stem. A study of 399 cases. J Arthroplasty 11:405-10

18. Retpen JB, Jensen JS (1993) Risk factors for recurrent aseptic loosening of the femoral component after cemented revision. J Arthroplasty 8:471-8

19. Retpen JB, Varmarken JE, Rock ND, Jensen JS (1992) Unsatisfactory results after repeated revision of hip arthroplasty. 61 cases followed for 5 (1-10) years. Acta Orthop Scand 63:120-7

20. Rubash HE, Harris WH (1988) Revision of nonseptic, loose, cemented femoral components using modern cementing techniques. J Arthroplasty 3:241-8 
21. Schreurs W, Chris Arts JJ, Verdonschot N, Buma P, Slooff T, Gardeniers J (2005) Femoral component revision with use of impaction bone-grafting and a cemented polished stem. J Bone Joint Surg Am 87:2499-2507

22. Stromberg CN, Herberts P (1996) Cemented revision total hip arthroplasties in patients younger than 55 years old. A multicenter evaluation of second generation cementing technique. J Arthroplasty 11:489-99
23. Weber KL, Callaghan JJ, Goetz DD, Johnston RC (1996) Revision of a failed cemented total hip prosthesis with insertion of an acetabular component without cement and a femoral component with cement. a five to eight-year follow-up study. J Bone Joint Surg Am 78:982-94

24. Wixson RL, Lautenschlager EP (1998) Methyl methacrylate. In: Callaghan JJ, Rosenberg AG, Rubash HE (eds) The adult hip. Lippincott-Raven, Philadelphia, pp 135-58 